\title{
Technical Lead
}

National Cancer Institute

\section{Source}

National Cancer Institute. Technical Lead. NCI Thesaurus. Code C154707.

An individual who is responsible for the delivery of technical aspects of a project. 